\author{
V.A. Romaka ${ }^{1,2}$, L.P. Romaka ${ }^{3}$, Yu.V. Stadnyk ${ }^{3}$, A.M. Horyn ${ }^{3}$, \\ V.Ya. Krayovskyy ${ }^{1}$, I.M. Romaniv ${ }^{3}$, P.I. Garanuyk ${ }^{1}$
}

\title{
Investigation of structural, electrokinetic and energy state properties of the semiconductive $\mathrm{Zr}_{1-x} \mathbf{V}_{x} \mathrm{NiSn}$ solid solution
}

\author{
${ }^{I}$ Ya. Pidstryhach Institute for Applied Problems of Mechanics and Mathematics National Academy of Sciences of Ukraine, 3-b, \\ Naukova Str., Lviv, 79060, Ukraine, e-mail:vromaka@polynet.lviv.ua; \\ ${ }^{2}$ National University "Lvivska Politechnika”, 12, S. Bandera Str., Lviv, 79013, Ukraine; \\ ${ }^{3}$ Ivan Franko National University of Lviv, 6, Kyryla and Mefodiya Str., Lviv, 79005, Ukraine, \\ e-mail: lyubov.romaka@gmail.com
}

\begin{abstract}
Structural, electrokinetic and energy state characteristics of the $\mathrm{Zr}_{1-x} \mathrm{~V}_{x} \mathrm{NiSn}$ semiconductive solid solution $(x=0-0.10)$ were investigated in the temperature interval $80-400 \mathrm{~K}$. It was shown that doping of the $\mathrm{ZrNiSn}$ compound by $\mathrm{V}$ atoms $\left(r_{\mathrm{V}}=0.134 \mathrm{~nm}\right)$ due to substitution of $\mathrm{Zr}\left(r_{\mathrm{Zr}}=0.160 \mathrm{~nm}\right)$ results in increase of lattice parameter $a(x)$ of $\mathrm{Zr}_{1-x} \mathrm{~V}_{x} \mathrm{NiSn}$ indicating unforecast strucrural change. Based on analysis of the motion rate of the Fermi level $\Delta \varepsilon_{\mathrm{F}} / \Delta x$ for $\mathrm{Zr}_{1-x} \mathrm{~V}_{x} \mathrm{NiSn}$ in direction of the conduction band it was concluded about simultaneous generation of the structural defects of the donor and acceptor nature (donor-acceptor pairs) by unknown mechanism and creation of the corresponding energy levels in the band gap of the semiconductor.
\end{abstract}

Keywords: solid solution, electrical conductivity, thermopower coefficient, Fermi level.

Article acted received 23.01.2019; accepted for publication 15.03.2019.

\section{Introduction}

The importance of the study of electroconductivity mechanism of the thermoelectric materials based on the $n$-ZrNiSn, $n$-HfNiSn and $n$-TiNiSn intermetallic semiconductors is due to the fact that thermoelectric materials based on the above-mentioned semiconductors have high efficiency of conversion of thermal energy into electric, and optimization of their characteristics is carried out by appropriate doping [1, 2].

The crystal structure of the intermetallic semiconductors was studied earlier. However, an analysis of the research results of the semiconductive solid solutions based on half-Heusler phases showed the difference (of several orders) between experimental measurements, for example, electrical resistivity and thermopower coefficient values and modeling of these characteristics by calculation of electronic structure. It's worth to note, that the basis of the calculation of the electronic structure by any method is the correct construction of the Wigner-Seitz cell in reciprocal space, which is the first Brillouin zone [1]. In other words, the degree of accordance of crystal structure model to real distribution of the atoms in the sites of the unit cell (or their absence - vacancies) determines the degree of accordance of the semiconductor's characteristics, obtained by modeling, to the results of experimental measurements.

What is the reason of such unpredictability and discrepancy?

Analysis of the Zr-Ni-Sn phase diagram in Ref. [3] showed a coexistence of the two related compounds, namely $\mathrm{ZrNiSn}$ (half-Heusler phase, space group $F \overline{4} 3 m$ ) and $\mathrm{ZrNi}_{2} \mathrm{Sn}$ (Heusler phase, space group $F m \overline{3} m$ ) [4]. Absence of center of symmetry in $\mathrm{ZrNiSn}$ is caused by covalent bonds between atoms, which results in the semiconductor properties, and forms in the unit cell the volume, not occupied by atoms (tetrahedral voids) (Fig. 1a), which is $\sim 24 \%$ of the total. The term "relation" means the following. If to assume, that these voids are occupied by smaller $\mathrm{Ni}$ atoms and to consider void as a vacancy (Vac) in $4 d$ position of Heusler phase, then the filling of $4 d$ position by $\mathrm{Ni}$ atoms results in change of symmetry and realization of the $\mathrm{ZrNi}_{2} \mathrm{Sn}$ compound at certain Ni concentration (Fig. 1, b).

The complex investigation of crystal and electronic structures, thermodynamic, electrokinetic and energy state characteristics of $\mathrm{ZrNi}_{1-x} \mathrm{Rh}_{x} \mathrm{Sn}$ semiconductive solid solution showed complicate change in the crystal and electronic structures $[5,6]$ caused by simultaneous 

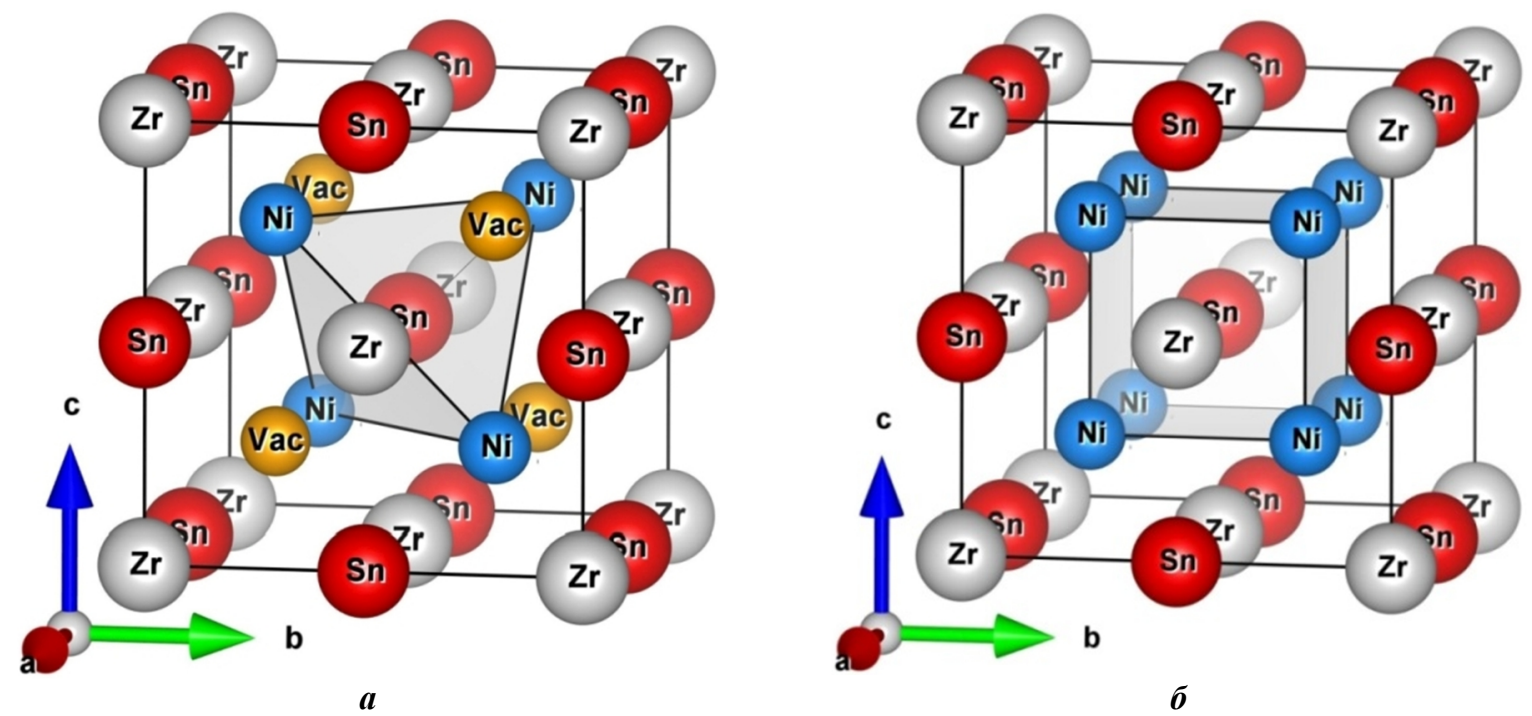

Fig. 1. Transformation of crystal structure of $\mathrm{ZrNiSn}(\boldsymbol{a})$ compound into $\mathrm{ZrNi}_{2} \mathrm{Sn}(\boldsymbol{b})$ due to accumulation of additional $\mathrm{Ni}$ atoms in tetrahedral voids of structure (occupation of vacancies by $\mathrm{Ni}$ atoms).

generation of the structural defects of acceptor and donor nature. It was shown an energy advantage of occupation $4 c$ position of $\mathrm{Ni}\left(3 d^{8} 4 s^{2}\right)$ atoms by $\mathrm{Rh}\left(4 d^{8} 5 s^{1}\right)$ atoms which generates the structural defects of acceptor nature (Ni has more $s$-electrons) and creates an impurity acceptor band $\varepsilon_{\mathrm{A}}{ }^{1}$ in the band gap. At the same time, part of the replaced $\mathrm{Ni}$ atoms is accumulated in tetrahedral voids (vacancies), generating the structural defects of donor nature, and in the band gap the deep donor band $\varepsilon_{\mathrm{D}}^{2}$ appears.

According to previous studies it was established that structure of the basic $\mathrm{ZrNiSn}$ compound is disordered as a result of partial, up to $\sim 1 \%(z=0.01)$, occupation of $4 a$ position of $\mathrm{Zr}\left(4 d^{2} 5 s^{2}\right)$ atoms by $\mathrm{Ni}\left(3 d^{8} 4 s^{2}\right)$ atoms, which generates the structural defects of donor nature and corresponding donor band $\varepsilon_{\mathrm{D}}{ }^{1}$ (Ni has more $d$-electrons). Formula of the compound can be written as $\left(\mathrm{Zr}_{1-z} \mathrm{Ni}_{z}\right) \mathrm{NiSn}$ [3].

Recent investigations of $\mathrm{TiNiSn}_{1-x} \mathrm{Ga}_{x}$ [7] and $\mathrm{ZrNiSn}_{1-x} \mathrm{Ga}_{x}$ [8] semiconductive solid solutions revealed an earlier unknown mechanism of generation of the structural defects of donor nature which suggests the appearance of vacancies in $4 b$ position of $\mathrm{Sn}$ atoms. It was established that in the case of doping of $n$-TiNiSn and $n-\mathrm{ZrNiSn}$ by $\mathrm{Ga}\left(4 s^{2} 4 p^{1}\right)$ atoms due to substitution of Sn $\left(5 s^{2} 5 p^{2}\right)$ in the same crystallographic position $4 b$ the defects of acceptor nature ( $\mathrm{Ga}$ has less $p$-electrons than $\mathrm{Sn}$ ) and donor nature (vacancies in position of $\mathrm{Sn}$ atoms) are generated. The concentration of the defects increases with $\mathrm{Ga}$ content, and semiconductors become heavily doped and highly compensated (HDHCS) [9]. At first sight, such unexpected result is logical, since the stability of structure and the principle of electroneutrality for the crystals of $\mathrm{TiNiSn}_{1-x} \mathrm{Ga}_{x}$ and $\mathrm{ZrNiSn}_{1-x} \mathrm{Ga}_{x}$ in the case of significant number of acceptors $\left(N_{\mathrm{A}}^{\mathrm{Ga}} \approx 3 \cdot 10^{21} \mathrm{~cm}^{-3}\right)$ are provided by the generation of structural defects of donor nature, the effective charge of which is the opposite. In this case, the formulas of the solid solutions can be written as $\mathrm{TiNiSn}_{1-x-y} \mathrm{Ga}_{x}$ and $\mathrm{ZrNiSn}_{1-x-y} \mathrm{Ga}_{x}$, where $y$ is the concentration of vacancies in $4 b$ position of $\mathrm{Sn}$ atoms.
In this context, the question arises why in case of doping of $\mathrm{ZrNiSn}$ compound by $\mathrm{Rh}$ atoms $\left(r_{\mathrm{Rh}}=0.134 \mathrm{~nm}\right)$ the part of the smallest size $\mathrm{Ni}$ atoms $\left(r_{\mathrm{Ni}}=0.124 \mathrm{~nm}\right) \quad$ occupies the tetrahedral voids generating donors, and in case of doping by Ga atoms $\left(r_{\mathrm{Ga}}=0.141 \mathrm{~nm}\right)$ this mechanism is not identified? What factor, dimensional, charge or other determines the method of generation of structural defects in semiconductive solid solutions based on half-Heusler phases, forming the electronic structure and electrical conduction mechanisms?

The search of answer for these questions the first experimental stage of the study of generation mechanisms for structural defects in $n$ - $\mathrm{ZrNiSn}$ doped by $\mathrm{V}$ atoms $\left(r_{\mathrm{V}}=0.134 \mathrm{~nm}\right)$ due to substitution of $\mathrm{Zr}$ is devoted to. Since V $\left(3 d^{3} 4 s^{2}\right)$ atom has one $d$-electron more than $\mathrm{Zr}$, the structural defects of donor nature should be generated in $\mathrm{Zr}_{1-x} \mathrm{~V}_{x} \mathrm{NiSn}$, and corresponding impurity donor level would have appear in the band gap. It worth to note that atomic radii of $\mathrm{Rh}$ and $\mathrm{V}$ are the same, but the way of their introduction in the structure of the compound is different.

\section{Experimental}

The samples of the $\mathrm{Zr}_{1-x} \mathrm{~V}_{x} \mathrm{NiSn}$ solid solution were synthesized by direct arc-melting of the constituent elements (content of the basic component not lower than 99.9 wt. \%) in electric arc-furnace under inert atmosphere. The pieces of the alloys were homogenized in evacuated silica tubes at $1073 \mathrm{~K}$ for $720 \mathrm{~h}$ and subsequently quenched in ice water. Phase analysis was performed using X-ray powder diffraction of the synthesized samples (diffractometer DRON-4.0 with $\mathrm{Fe} K_{\alpha}$ radiation). The calculation of the crystallographic parameters was performed using the Fullprof program package [10]. Chemical and phase compositions of the samples were examined by electron microprobe analysis (EPMA) (scanning electron microscope REMMA 102$02)$. Temperature and concentration dependences of the electrical resistivity $(\rho)$ and thermopower coefficient $(\alpha)$ 
(copper as a reference material) of the $\mathrm{Zr}_{1-x} \mathrm{~V}_{x} \mathrm{NiSn}$ samples were measured in the temperature range $T=80-400 \mathrm{~K}$ and concentration interval $N_{\mathrm{D}}^{\mathrm{V}} \approx 3.8 \cdot 10^{19} \mathrm{~cm}^{-3} \quad(x=0.005) \div 1.9 \cdot 10^{21} \quad \mathrm{~cm}^{-3}$ $(x=0.10)$.

\section{Study of crystallographic characteristics of $\mathbf{Z r}_{1-x} \mathbf{V}_{x} \mathrm{NiSn}$}

$\mathrm{X}$-ray phase and structural analyses showed that the prepared $\mathrm{Zr}_{1-x} \mathrm{~V}_{x} \mathrm{NiSn}$ samples were single phases, and the powder patterns were indexed with cubic MgAgAs structure type (space group F-43m) [4]. Mictrostructure analysis of the atomic concentration on the surface of the $\mathrm{ZrNi}_{1-x} \mathrm{Rh}_{x} \mathrm{Sn}$ samples indicated their accordance to initial compositions of the ingots. Since the atomic radius of $\mathrm{V} \quad\left(r_{\mathrm{V}}=0.134 \mathrm{~nm}\right)$ is smaller than that of $\mathrm{Zr}$ $\left(r_{\mathrm{Zr}}=0.160 \mathrm{~nm}\right)$, it was expected to decrease the values of lattice parameter $a(x)$ for $\mathrm{Zr}_{1-x} \mathrm{~V}_{x} \mathrm{NiSn}$. However, the results of structural studies for $\mathrm{Zr}_{1-x} \mathrm{~V}_{x} \mathrm{NiSn}$ showed a clear tendency to increase of $a(x)$ (Fig. 2) at least to values of $x=0.07$.

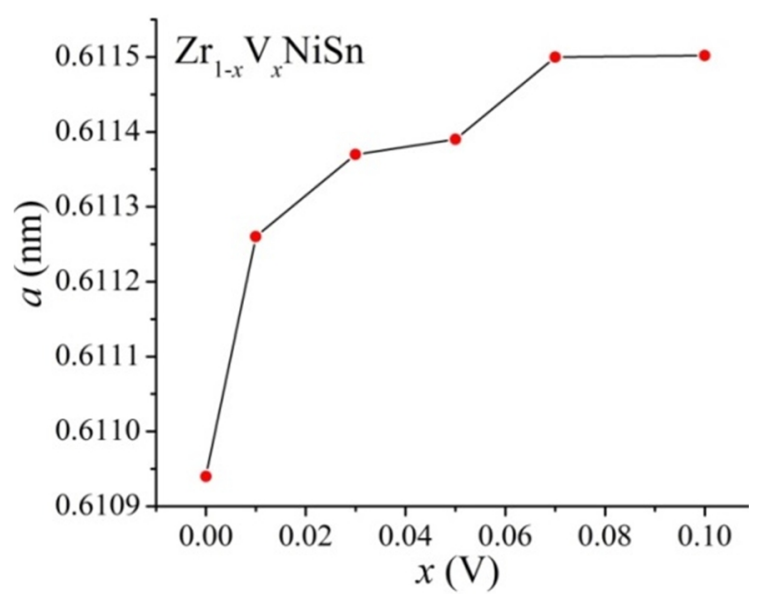

Fig. 2. Variation of lattice parameter $a(x)$ for $\mathrm{Zr}_{1-x} \mathrm{~V}_{x} \mathrm{NiSn}$

Such behavior of the lattice parameter $a(x)$ of $\mathrm{Zr}_{1-x} \mathrm{~V}_{x} \mathrm{NiSn}$ was unexpected, and the refinement of crystal structure due to the insignificant content of impurity which concentration is far beyond the precision of device did not give definit answer to the way of introduction of $\mathrm{V}$ atoms into the $\mathrm{ZrNiSn}$ structure. This experimental result is the first important feature that in the structure of $\mathrm{Zr}_{1-x} \mathrm{~V}_{x} \mathrm{NiSn}$ semiconductor there are unpredictable changes which will be the source of structural defects that will determine its properties. The fact that the lattice parameter did not change in the concentration interval $x=0.07-0.10$ may indicate the limited solubility of $\mathrm{V}$ in the semiconductor matrix, which can be caused by the appearance of small amount of metallic phase which we did not identify.

The growth of $a(x)$ dependence of $\mathrm{Zr}_{1-x} \mathrm{~V}_{x} \mathrm{NiSn}$ is possible, for example, due to unexpected occupation of the crystallographic position $4 c$ of the smaller $\mathrm{Ni}$ atoms $\left(r_{\mathrm{Ni}}=0.124 \mathrm{~nm}\right)$ by $\mathrm{V}$ atoms. In this case, the structural defects of acceptor nature will be generated in the crystallographic position $4 c$, because $\mathrm{Ni}\left(3 d^{8} 4 s^{2}\right)$ has more $3 d$-electrons than $\mathrm{V}\left(3 d^{3} 4 s^{2}\right)$. On the other hand, in the case of occupation of tetrahedral voids by replaced $\mathrm{Ni}$ atoms similarly to $\mathrm{ZrNi}_{1-x} \mathrm{Rh}_{x} \mathrm{Sn}[5,6]$, the structural defects of donor nature are also generated in the $\mathrm{Zr}_{1-x} \mathrm{~V}_{x} \mathrm{NiSn}$ crystal. As a result, the obtained $\mathrm{Zr}_{1-x} \mathrm{~V}_{x} \mathrm{NiSn}$ samples will be HDHCS [9].

\section{III.Study of electrokinetic and energy state characteristics of $\mathrm{Zr}_{1-x} \mathrm{~V}_{x} \mathrm{NiSn}$}

The temperature and concentration dependences of electrical resistivity $\rho$ and thermopower coefficient $\alpha$ for $\mathrm{Zr}_{1-x} \mathrm{~V}_{x} \mathrm{NiSn}$ are shown in Figs. 3, 4.

The dependences $\ln \rho(1 / T)$ and $\alpha(1 / T)$ for $\mathrm{Zr}_{1-x} \mathrm{~V}_{x} \mathrm{NiSn}$ (Fig. 3) are typical for heavily doped and highly compensated semiconductors [9], and presence of activation regions indicates several mechanisms of charge transport. These mechanisms are the activation of current carriers from the Fermi level $\varepsilon_{\mathrm{F}}$ to continuous energy band (high temperatures) and hopping conductivity within the energy states close to Fermi level $\varepsilon_{\mathrm{F}}$ (low temperatures). The dependences of $\ln \rho(1 / T)$ for $\mathrm{Zr}_{1-x} \mathrm{~V}_{x} \mathrm{NiSn}$ are described by known relation [9]:

$$
\rho^{-1}(T)=\rho_{1}^{-1} \exp \left(-\frac{\varepsilon_{1}^{\rho}}{k_{B} T}\right)+\rho_{3}{ }^{-1} \exp \left(-\frac{\varepsilon_{3}^{\rho}}{k_{B} T}\right)
$$

where the first term describes an activation of current carriers from the Fermi level $\varepsilon_{\mathrm{F}}$ to continuous energy band at high temperatures and second term at low temperatures - hopping conductivity $\varepsilon_{3}{ }^{\rho}$.

The temperature dependences of thermopower coefficient $\alpha(1 / T)$ for $\mathrm{Zr}_{1-x} \mathrm{~V}_{x} \mathrm{NiSn}$ are described by relation [11]:

$$
\alpha=\frac{k_{B}}{e}\left(\frac{\varepsilon_{i}^{\alpha}}{k_{B} T}-\gamma+1\right),
$$

where $\gamma$ - parameter which depends on the scattering mechanism. From the high temperature part of $\alpha(1 / T)$ dependences the activation energy values $\varepsilon_{1}{ }^{\alpha}$ which are proportional to amplitude of high-scale fluctuation of the continuous energy bands were calculated. From the low temperature part of the $\alpha(1 / T)$ dependences the activation energy values $\varepsilon_{3}{ }^{\alpha}$ which are proportional to amplitude of the small-scale fluctuation HDHCS $[1,9]$ were obtained.

From the high-temperature part of the $\ln \rho(1 / T)$ dependence for undoped $n-\mathrm{ZrNiSn}$ semiconductor (Fig. 3 , a) the values of activation energy of electrons from donor band $\varepsilon_{\mathrm{D}}{ }^{1}$ to the percolation level of conduction band were calculated: $\varepsilon_{1}{ }^{\rho}=97.6 \mathrm{meV}$. The activation of electrons to the conduction band was confirmed by negative values of the thermopower coefficient of $n$ $\mathrm{ZrNiSn}$ at all temperatures. Since the Fermi level $\varepsilon_{\mathrm{F}}$ is fixed at the donor band $\varepsilon_{\mathrm{D}}{ }^{1}$, the calculated activation energy value of electrons $\varepsilon_{1}{ }^{\rho}$ represents the location depth of the Fermi level $\varepsilon_{\mathrm{F}}$ relatively to the edge of the conduction band. Obtained result agrees with previously one [1]. The presence of low-temperature activation on dependence of $\ln \rho(1 / T)$ indicated the existence of the hopping conductivity over the energy states of donor band $\varepsilon_{\mathrm{D}}{ }^{1}$ with activation energy $\varepsilon_{3}{ }^{\rho}=11.9 \mathrm{meV}$. Additionally, from high- and low-temperatures parts of 


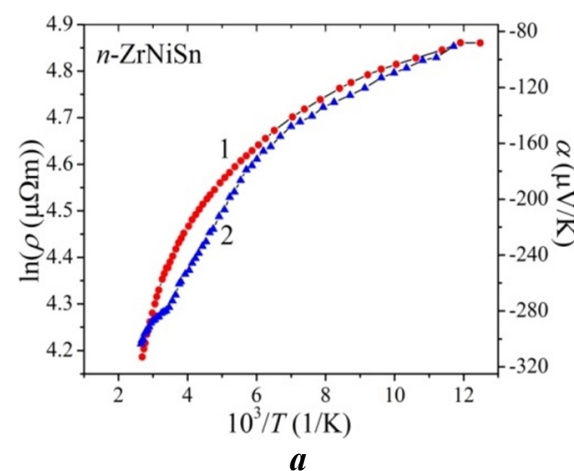

$\boldsymbol{a}$
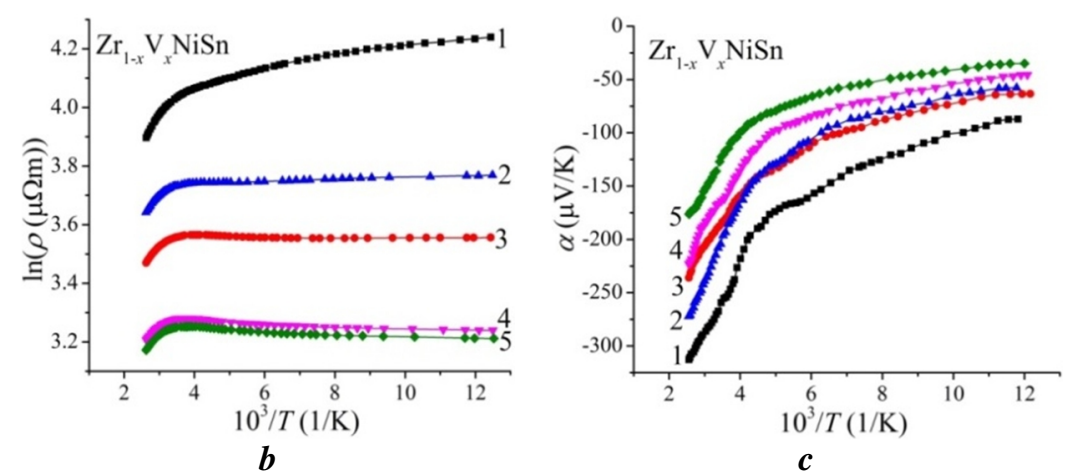

Fig. 3. Temperature dependences of electrical resistivity $\ln \rho(1 / T)(1)$ and thermopower coefficient $\alpha(1 / T)$ (2) for $n$-ZrNiSn $(\boldsymbol{a})$ and $\ln \rho(1 / T)(\boldsymbol{b})$ and $\alpha(1 / T)(\boldsymbol{c})$ for $\mathrm{Zr}_{1-x} \mathrm{~V}_{x} \mathrm{NiSn}: 1-x=0.01 ; 2-x=0.03 ; 3-x=0.05$;

$$
4-x=0.07 ; 5-x=0.10 \text {. }
$$

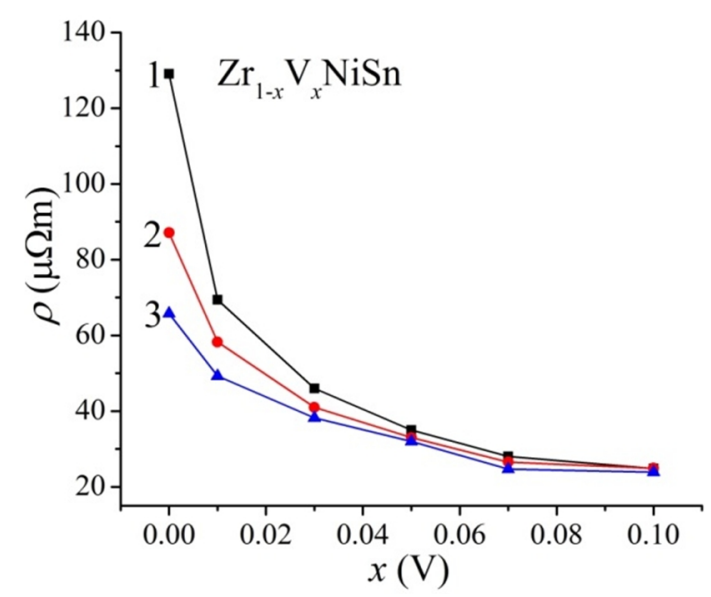

$a$

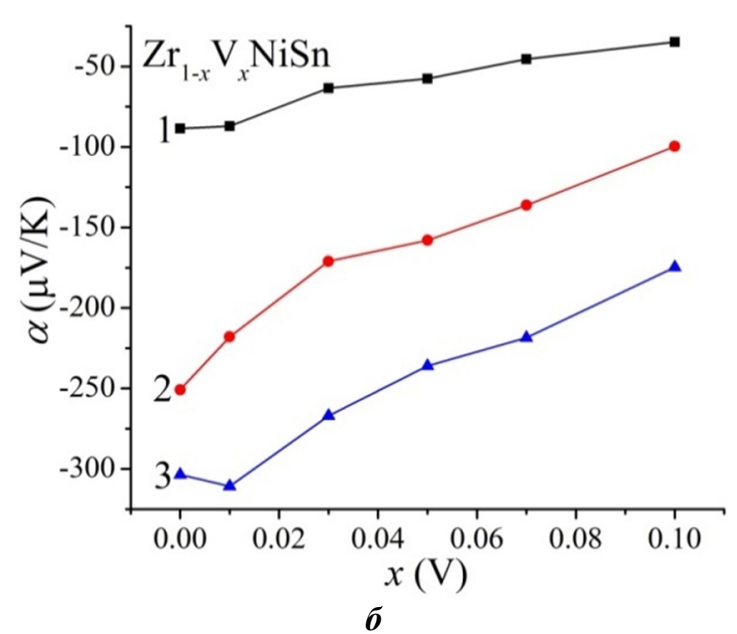

б

Fig. 4. Variation of electrical resistivity values $\rho(x)$ (a) and thermopower coefficient $\alpha(x)(\boldsymbol{b})$ for $\mathrm{Zr}_{1-x} \mathrm{~V}_{x} \mathrm{NiSn}$ at different temperatures: $1-T=80 \mathrm{~K} ; 2-T=250 \mathrm{~K} ; 1-T=380 \mathrm{~K}$.

$\alpha(1 / T)$ dependence the activation energy values $\varepsilon_{1}{ }^{\alpha}=83.8 \mathrm{meV}$ and $\varepsilon_{3}{ }^{\alpha}=11.5 \mathrm{meV}$, respectively, were determined. Since the value of activation energy $\varepsilon_{1}{ }^{\alpha}$ represents the modulation amplitude of continues energy band of $n$-ZrNiSn [1,9], the close values of $\varepsilon_{1}{ }^{\alpha}$ and $\varepsilon_{1}{ }^{\rho}$ are a feature of high compensation of the semiconductor.

Doping of $\mathrm{ZrNiSn}$ compound by $\mathrm{V}$ impurity atoms results in the change of behavior of $\ln \rho(1 / T)$ and $\alpha(1 / T)$ dependences and the values of electrical resistivity and thermopower coefficient (Fig. 3, 4). Since the substitution of $\mathrm{Zr}$ atoms by $\mathrm{V}$ would have generate in the $\mathrm{Zr}_{1-x} \mathrm{~V}_{x} \mathrm{NiSn}$ crystal the structural defects of donor nature, an increase of the concentration of free electrons should lead to the decrease of the electrical resistivity values $\rho(x, T)$, as it's shown in Fig. 4, a. At the same time, the sign of thermopower coefficient $\alpha(x, T)$ for $\mathrm{Zr}_{1-x} \mathrm{~V}_{x} \mathrm{NiSn}$ remains negative at all concentrations and temperatures (Fig. 4, b).

As it was noted above, the $\mathrm{ZrNiSn}$ structure is disordered due to the partial occupation of $4 a$ position of $\mathrm{Zr}$ atoms by $\mathrm{Ni}$ atoms which generates the structural defects of donor nature. Studies of the crystal structure of semiconductive solid solutions, in particular $\mathrm{Zr}_{1-x} \mathrm{R}_{x} \mathrm{NiSn}$ ( $\mathrm{R}$ - rare earth atoms), $\mathrm{ZrNi}_{1-x} \mathrm{M}_{x} \mathrm{Sn}$, where $\mathrm{M}=\mathrm{Cr}, \mathrm{Mn}$, $\mathrm{Fe}, \mathrm{Co}, \mathrm{Ni}, \mathrm{Cu}, \mathrm{Rh}, \mathrm{Ru}$, etc., [1], showed that at concentration $x \approx 0.01$ all $\mathrm{Ni}$ atoms are displaced from $4 a$ position. As result, the structure becomes ordered, and the defects of donor nature are "healed". Thus, in the case of $\mathrm{Zr}_{1-x} \mathrm{~V}_{x} \mathrm{NiSn}$ within concentration range $x=0$ 0.01 dynamic variation of the ratio of donors and acceptors (compensation degree) takes place, which is caused by:

- increase of the electron concentration due to appearance of the impurity donor band $\varepsilon_{D}^{2}$ and increase of the donor number due to substitution of the $\mathrm{Zr}$ atoms by $\mathrm{V}$ atoms;

- decrease of the electron concentration caused by disappearance of the impurity donor band $\varepsilon_{\mathrm{D}}^{2}$ due to ordering of $\mathrm{Zr}_{1-x} \mathrm{~V}_{x} \mathrm{NiSn}$ structure as a result of displacement of the $\mathrm{Ni}$ atoms from $4 a$ position of $\mathrm{Zr}$ atoms ("healing" of the defects of donor nature).

At higher $\mathrm{V}$ concentration $(x>0.01)$ only the structural defects of donor nature should be generated in the semiconductor, that will result in enlarge of the electron concentration and decrease of the electrical resistivity values as shown in Fig. 3, a and 4, a.

The presence of high-temperature activation parts in the $\ln \rho(1 / T)$ dependences of $\mathrm{Zr}_{1-x} \mathrm{~V}_{x} \mathrm{NiSn}$ even at "giant" concentration of the donor impurity $\left(N_{\mathrm{D}} \mathrm{V} \approx 1.9 \cdot 10^{21} \mathrm{~cm}^{-3}\right.$ for $x=0.10$ ) (Fig. $3, b$ ) and negative values of the thermopower coefficient $\alpha(x, T)$ indicate that the Fermi level $\varepsilon_{\mathrm{F}}$ is located in the band gap near the bottom of the 
conduction band. This experimental fact is the second feature that in the semiconductor $\mathrm{Zr}_{1-x} \mathrm{~V}_{x} \mathrm{NiSn}$, besides donors, the defects of acceptor nature appear by unknown mechanism and compensate the donors (catch free electrons increasing their concentration). As a result the movement of Fermi level $\varepsilon_{\mathrm{F}}$ to the conduction band becomes slower.

It's worth to remind that the doping of $n-\mathrm{ZrNiSn}$, for example, by donor impurity $\mathrm{Sb}\left(4 d^{10} 5 s^{2} 5 p^{3}\right)$ due to substitution of $\mathrm{Sn}\left(4 d^{10} 5 s^{2} 5 p^{2}\right)$ leads to rapid drift of the Fermi level $\varepsilon_{\mathrm{F}}$ to the bottom of the conduction band and crossing of this band at the concentration $\mathrm{Sb} x \approx 0.02$, which was accompanied by metallization of the conductivity of $\mathrm{ZrNiSn}_{1-x} \mathrm{Sb}_{x}$ [1]. In the case of $\mathrm{Zr}_{1-x} \mathrm{~V}_{x} \mathrm{NiSn}$ the metallization of conductivity (disappearance of activation part in $\ln \rho(1 / T)$ dependence) was not observed at all temperatures and concentrations.

On the other hand, the presence of high-temperature activation parts in $\ln \rho(1 / T)$ dependence of $\mathrm{Zr}_{1-x} \mathrm{~V}_{x} \mathrm{NiSn}$ (Fig. 3,b) allows to calculate the values of activation energy of electrons $\varepsilon_{1}{ }^{\rho}(x)$ from the Fermi level $\varepsilon_{\mathrm{F}}$ to the mobility edge of the conduction band and to trace dynamics of the Fermi level position $\varepsilon_{\mathrm{F}}$ in the band gap of the semiconductor. From the activation parts of $\alpha(1 / T)$ dependences we can obtain information concerning with the change of compensation degree for $\mathrm{Zr}_{1-x} \mathrm{~V}_{x} \mathrm{NiSn}$ by calculation of activation energy values $\varepsilon_{1}{ }^{\alpha}$ which are proportional to the amplitude of large-scale fluctuation of continuous energy bands in HDHCS.

The variation of activation energy values $\varepsilon_{1}{ }^{\rho}(x)$ and $\varepsilon_{1}{ }^{\alpha}(x)$ for $\mathrm{Zr}_{1-x} \mathrm{~V}_{x} \mathrm{NiSn}$ is presented in Fig. 5. At the lowest impurity concentration of $\mathrm{Zr}_{1-x} \mathrm{~V}_{x} \mathrm{NiSn}, x=0.01$, the Fermi level $\varepsilon_{\mathrm{F}}$ with motion rate $\Delta \varepsilon_{\mathrm{F}} / \Delta x \approx 77.8 \mathrm{meV} / \% \mathrm{~V}$ rapidly approached the percolation level of conduction band at the distance of $19.8 \mathrm{meV}$, while in $n$-ZrNiSn it was located at the distance of $97.6 \mathrm{meV}$. And this despite the fact that in this concentration range there was a decrease of the electron concentration due to the disappearance of impurity donor band $\varepsilon_{\mathrm{D}}{ }^{1}$ caused by ordering of $\mathrm{Zr}_{1}$ ${ }_{x} \mathrm{~V}_{x} \mathrm{NiSn}$ structure, which would have to slow down the Fermi level $\varepsilon F$ in the direction of conduction band. With the same rate the Fermi level $\varepsilon_{\mathrm{F}}$ moved to the percolation

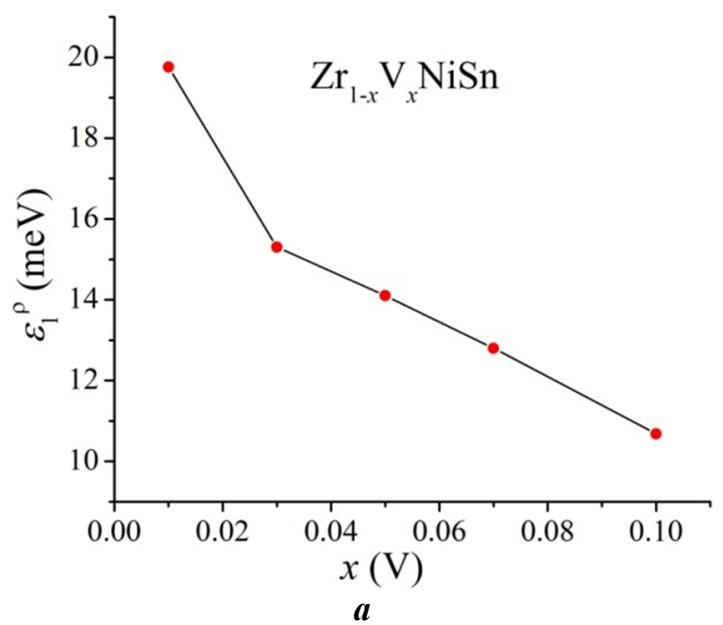

level of conduction band in the case of doping of $n$ ZrNiSn by donor impurity Sb [1].

However, at higher concentrations $\mathrm{V}$, the rapid decrease of motion rate of Fermi level $\varepsilon_{\mathrm{F}}$ in the direction to conduction band takes place. Thus, in the concentration interval $x=0.01-0.03$, the motion rate of Fermi level $\varepsilon_{\mathrm{F}}$ is $\Delta \varepsilon_{\mathrm{F}} / \Delta x \approx 2.2 \mathrm{meV} / \% \mathrm{~V}$, at concentrations $x=0.03-0.10$ becomes even smaller and is equal $\Delta \varepsilon_{\mathrm{F}} / \Delta x \approx 0.7 \mathrm{meV} / \% \mathrm{~V}$. Since the concentration of impurity $\mathrm{V}$ atoms, which should generate donors, is introduced into the matrix of $n$ - $\mathrm{ZrNiSn}$ semiconductor according to the linear law, then the Fermi level $\varepsilon_{\mathrm{F}}$ would have to move to the percolation level of conduction band of $\mathrm{Zr}_{1-x} \mathrm{~V}_{x} \mathrm{NiSn}$ in the same way. What is the reason for "braking" of this motion?

From the point of view of semiconductor physics it is possible only if simultaneously with donors the generation of acceptors takes place by unknown mechanism. Thus, obtained experimental result is the third indisputable feature, which confirms, except donors, the appearance of some number of acceptors in $\mathrm{Zr}_{1-x} \mathrm{~V}_{x} \mathrm{NiSn}$, which generation rate is lower than generation rate of donors, because the Fermi level $\varepsilon_{\mathrm{F}}$ is still approaching to the percolation level of conduction band, as indicated by negative values of thermopower coefficient.

This conclusion is consistent with the results of change of activation energy values $\varepsilon_{1}^{\alpha}(x)$ for $\mathrm{Zr}_{1-x} \mathrm{~V}_{x} \mathrm{NiSn}$, $x \geq 0.01$, (Fig. 5,b), which reflects the compensation degree of semiconductor. Since the dependence of $\varepsilon_{1}{ }^{\alpha}(x)$ represents the ratio of ionized acceptors and donors, the total number of donors exceeds the number of acceptors in $\mathrm{Zr}_{1-x} \mathrm{~V}_{x} \mathrm{NiSn}$, provided that the sign of thermopower coefficient is negative. The compensation degree and $\varepsilon_{1}{ }^{\alpha}(x)$ values become lower with increasing this exceedation.

Thus, in $\mathrm{Zr}_{1-x} \mathrm{~V}_{x} \mathrm{NiSn}$ the reduction of compensation degree initially takes place, as indicated by decrease of energy activation values from $\varepsilon_{1}^{\alpha}(x=0)=83.8 \mathrm{meV}$ to $\varepsilon_{1}^{\alpha}(x=0.01)=60.1 \mathrm{meV}$ and $\varepsilon_{1}{ }^{\alpha}(x=0.03)=52.5 \mathrm{meV}$. Such decrease of $\varepsilon_{1}{ }^{\alpha}(x)$ values, as well as the motion rate of Fermi level $\varepsilon_{\mathrm{F}}$ to the the conduction band, is also nonlinear. However, at concentration $x>0.03$, the

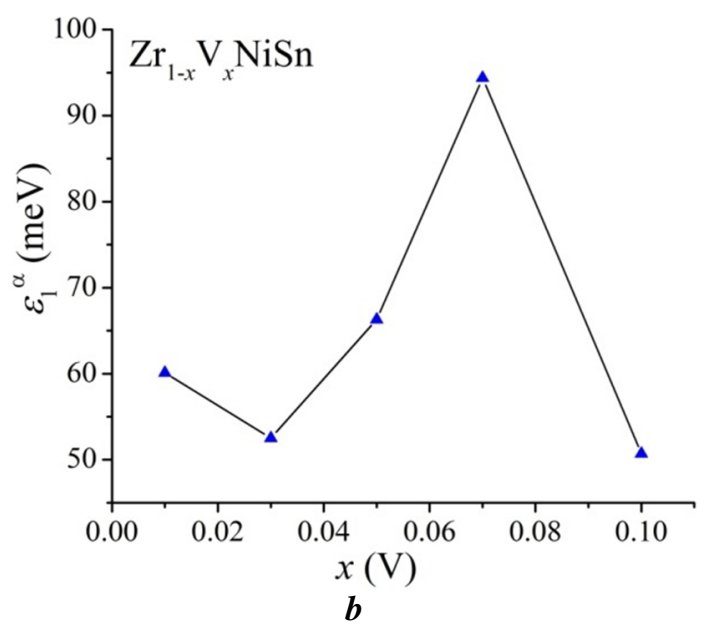

Fig. 5. Variation of activation energy values $\varepsilon_{1}{ }^{\rho}(x)(\boldsymbol{a})$ and $\varepsilon_{1}{ }^{\alpha}(x)(\boldsymbol{b})$ for $\mathrm{Zr}_{1-x} \mathrm{~V}_{x} \mathrm{NiSn}$. 
dependence $\varepsilon_{1}{ }^{\alpha}(x)$ rapidly increases with maximum at $x=0.07$, indicating that in the crystal acceptors are generated with larger rate than donors, but the total number of ionized donors is still higher than ionized acceptors. The obtained result is an additional factor that indicates the simultaneous generation of acceptors and donors in $\mathrm{Zr}_{1-x} \mathrm{~V}_{x} \mathrm{NiSn}$. Taking into account the structural investigations, we consider that the activation energy values $\varepsilon_{1}{ }^{\alpha}(x=0.10)=50.7 \mathrm{meV}$ do not correspond to real state in the semiconductor due to possible shunting of current by channels of admixture phase.

Consequently, the presented experimental results of electrokinetic and energy state studies confirmed the predicted complicated character of introduction of $\mathrm{V}$ atoms into the structure of $\mathrm{Zr}_{1-x} \mathrm{~V}_{x} \mathrm{NiSn}$ semiconductor, as evidenced by the unexpected increase of unit cell parameter $a(x)$ (Fig. 2). Performed analysis shows that an increase of lattice parameter $a(x)$, on the one hand, and the appearance of acceptors in $\mathrm{Zr}_{1-x} \mathrm{~V}_{x} \mathrm{NiSn}$, on the other hand, can only be achieved by the partial occupation of $4 c$ position of smaller $\mathrm{Ni}$ atoms $\left(r_{\mathrm{Ni}}=0.124 \mathrm{~nm}\right)$ by $\mathrm{V}$ atoms. If the displaced $\mathrm{Ni}$ atoms occupy the tetrahedral voids of the structure, as in the case of $\mathrm{ZrNi}_{1-x} \mathrm{Rh}_{x} \mathrm{Sn}$ $[5,6]$, then structural defects of the donor nature will also be generated in $\mathrm{Zr}_{1-x} \mathrm{~V}_{x} \mathrm{NiSn}$.

These considerations need confirmation by electronic structure calculations for various variants of atomic distribution in the matrix of semiconductor, which will show the motion of Fermi level $\varepsilon_{\mathrm{F}}$. The comparison of calculations with experimental results described above will give final answer about mechanism of introduction of $\mathrm{V}$ atoms into the $n-\mathrm{ZrNiSn}$ structure. That will be the subject of our next studies.

\section{Conclusions}

Thus, based on the abovementioned results we can suppose that to provide the stability of the structure and the principle of electroneutrality in $\mathrm{Zr}_{1-x} \mathrm{~V}_{x} \mathrm{NiSn}$ the structural defects of acceptor and donor nature (the effective charge of which is opposite) are generated simultaneously, the concentration of which enlarges with the increase of $\mathrm{V}$ content. Determination of the mechanisms for generation of acceptors and donors need additional investigation of the $\mathrm{Zr}_{1-x} \mathrm{~V}_{x} \mathrm{NiSn}$ solid solution, to which our next work will be devoted.

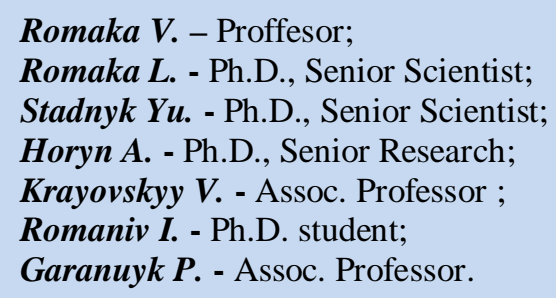

[1] V. A. Romaka, V. V. Romaka, and Yu. V. Stadnyk, Intermetallic Semiconductors: Properties and Applications (Lviv, Lvivska Politekhnika, 2011) [in Ukrain].

[2] L. I. Anatychuk, Termoelements and Thermoelectric Devices (Kiev, Nauk. Dumka, 1979) [in Ukrain].

[3] V.V. Romaka, P. Rogl, L. Romaka, Yu. Stadnyk, A. Grytsiv, O. Lakh, V. Krayovskyy, Intermetallics 35, 45 (2013). (DOI:doi.org/10.1016/j.intermet.2012.11.022).

[4] V.V. Romaka, L.P. Romaka, V.Ya. Krayovskyy, Yu.V. Stadnyk, Stannides of rare earths and transition metals (Lviv polytechnic university, Львів, 2015).

[5] L.P. Romaka, Yu.V. Stadnyk, V.A. Romaka, A.M. Goryn, V.Ya. Krayovskyy, Physics and Chemistry of Solid State, 19(1), 21 (2018). (DOI:doi: 10.15330/pcss.19.1.21-28).

[6] L.P. Romaka, Yu.V. Stadnyk, V.V. Romaka, P. Rogl, V.A. Romaka, A.M. Horyn, Physics and Chemistry of Solid State, 19(2), 151 (2018). (DOI:doi: 10.15330/pcss.19.2.151-158).

[7] V.A. Romaka, P. Rogl, L.P. Romaka, Yu.V. Stadnyk, V.Ya. Krayovskyy, D. Kacharovskii, A.M. Goryn, Journal of Thermoelectricity 3, 24 (2016).

[8] L.P. Romaka, Yu.V. Stadnyk, .A. Romaka, .M. Goryn, P. Rogl, V.Ya. Krayovskyy, Z.M. Rykavets, Physics and Chemistry of Solid State, 18 (1), 41 (2017). (DOI:doi: 10.15330/pcss.18.1.41-48).

[9] B. I. Shklovskii and A. L. Efros, Electronic Properties of Doped Semiconductors (Springer, NY, 1984).

[10] T. Roisnel, J. Rodriguez-Carvajal, Mater. Sci. Forum, Proc. EPDIC7, 378-381, 118 (2001).

[11] N.F. Mott, E.A. Davis, Electron processes in non-crystalline materials (Clarendon Press, Oxford, 1979). 
В.А. Ромака ${ }^{1,2}$, Л.П. Ромака ${ }^{3}$, Ю.В. Стадник ${ }^{3}$, А.М. Горинь ${ }^{3}$, В.Я. Крайовський ${ }^{1}$, І.М. Романів ${ }^{3}$, П.І. Гаранюк ${ }^{1}$

\title{
Дослідження структурних, кінетичних та енергетичних властивостей напівпровідникового твердого розчину $\mathrm{Zr}_{1-x} \mathrm{~V}_{x} \mathrm{NiSn}$
}

\author{
${ }^{1}$ Національний університет “Львівська політехніка”, вул. С. Бандери, 12, Львів, 79013, Україна, \\ e-mail: vromaka@lp.edu.ua; \\ ${ }^{2}$ Інститут прикладних проблем механіки і математики ім. Я.С. Підстригача НАН Украйни, \\ вул. Наукова, 3-б, Львів, 79060, Україна; \\ ${ }^{3}$ Львівський національний університет ім. І.Франка, вул. Кирила і Мефодія, 6, Львів, 79005, Украӥна, \\ e-mail:lyubov.romaka@gmail.com;
}

Досліджено особливості структурних, кінетичних та енергетичних характеристик напівпровідникового твердого розчину $\mathrm{Zr}_{1-x} \mathrm{~V}_{x} \mathrm{NiSn}(x=0-0,10)$ в інтервалі температур $80-400 \mathrm{~K}$. Показано, що уведення атомів $\mathrm{V}\left(r_{\mathrm{V}}=0,134\right.$ нм) у структуру сполуки $\mathrm{ZrNiSn}$ шляхом заміщення $\mathrm{Zr}$ $\left(r_{\mathrm{Zr}}=0,160\right.$ нм) супроводжується неочікуваним збільшенням значень періоду елементарної комірки $a(x)$ $\mathrm{Zr}_{1-x} \mathrm{~V}_{x} \mathrm{NiSn}$, вказуючи на непрогнозовані структурні зміни. На основі аналізу швидкості руху рівня Фермі $\Delta \varepsilon_{\mathrm{F}} / \Delta x \mathrm{Zr}_{1-x} \mathrm{~V}_{x} \mathrm{NiSn}$ у напрямі зони провідності зроблено висновок про одночасне генерування у кристалі структурних дефектів донорної та акцепторної природи (донорно-акцепторні пари) за невідомим механізмом, які породжують відповідні енергетичні рівні у забороненій зоні напівпровідника.

Ключові слова: твердий розчин, електропровідність, коефіцієнт термо-ерс, рівень Фермі. 